\title{
Trabalhadores da saúde sob risco: o uso de pulverizadores no controle de vetores
}

\author{
Rodolfo Andrade de Gouveia Vilela \\ Maria Elizabeth Malagoli \\ Santa Casa de São Paulo \\ Luiz C. Morrone \\ Santa Casa de São Paulo
}

Pós Graduação em Engenharia de Produção da UNIMEP

\begin{abstract}
Resumo
Objetivos: apresentar resultados de estudo ergonômico do trabalho dos desinsetizadores, destacando-se avaliação do ruído, calor e medidas de controle durante aplicação de inseticidas com pulverizador costal motorizado. Métodos: Reuniões com equipes, video-gravação e análise da atividade através do método preconizado por Guerin et al. (2001). Avaliação quantitativa do ruído e ensaios para redução deste através de modificações no equipamento. Medição do IST durante a pulverização, estudo da perda de peso corpóreo de expostos e não-expostos à radiação solar, antes e depois da atividade. Exames médicos dos trabalhadores. Resultados: nível equivalente de ruído medido foi $97,5 \mathrm{~dB}(\mathrm{~A})$ e em baixas freqüências acima de $100 \mathrm{~dB}$. IBUTG de 29,37º , para um LT de 25,5ํ․ Perda de peso dos expostos 2,31\% em média e 1,71\% para o grupo-controle. Conclusões: reestudos da forma de trabalho e de engenharia são necessários para redução de desgastes à saúde decorrentes da atividade e da concepção do equipamento.
\end{abstract}

Palavras-chave

Ergonomia, pulverizador costal motorizado, controle químico de vetores.

\section{Worker's Health at risk: the use of sprayers on the vectors control}

\begin{abstract}
Aims: Present results of ergonomic job analyze with emphasis at noise and heat evaluation and control during application of pesticides with. Methods: Based on Guerin et all [2001) such as meeting with team-workers, videorecords and job analyze. Quantitative evaluation of emitted noise from equipment. Experiments for noise level reduction through changes in the exhaust equipment and placement of sound barriers. Measurement of environment heat from solar radiation, through the Wet Bulb Globe Temperature Index. Study of weight loss before and after the spraying activities, comparing a group of exposed and not-exposed to solar radiation. Medical examination of the exposed workers. Results: The equivalent noise level is 97,5 dB (A), with high levels lover 100 $d B$ in the low frequencys. WBGT index was $29,37^{\circ} \mathrm{C}$. Weight loss in exposed workers was 2,31\% in average weight loss being 1,71\% in the control-group. Conclusions: New studies of work organization and engineering are needed to decrease damage caused by this equipment design and to reduce the health negative effects during the job activity.
\end{abstract}

\section{Key words}

Ergonomic, dorsal motorized spraying equipment, chemical vector's control. 


\section{ANÁLISE DA DEMANDA E OBJETIVOS DO TRABALHO}

O controle químico de vetores tem sido utilizado pelos órgãos públicos como uma das maneiras para evitar a propagação de epidemias como as de dengue, febre amarela, doença de chagas, leishmaniose entre outras.

O presente estudo é fruto das iniciativas adotadas para avaliar e gerenciar os riscos à saúde dos trabalhadores que aplicam inseticidas para o controle de vetores na Superintendência de Controle de Endemias SUCEN-SP. Ao cuidar da saúde da população, os funcionários da SUCEN colocam em risco sua própria saúde. Os autores participaram no período de 1998 a 2002 de um programa de minimização e controle dos riscos à saúde dos trabalhadores implantado por meio de um convênio mantido pela SUCEN e pelo Centro de Estudos Augusto Leopoldo Ayrosa Galvão (CEALAG), entidade de pesquisa vinculada à Faculdade de Ciências Médicas da Santa Casa de São Paulo. mesmo período a cobertura atingida para este exame foi de somente $37 \%$, conforme consta no relatório anual de PCMSO ano 2001/02, o que significa que este número pode ser três vezes maior.

Nos exames médicos realizados nos "desins" no referido período, foram ainda encontrados 50 casos de queixas de dores na região lombar - dorso - e cervicalgia intermitente. As patologias da coluna foram as principais causas de restrição médica ao trabalho, com 10 casos de hérnia de disco comprovados em exames complementares de imagem. Em dois casos as tendinopatias de ombro foram responsáveis por afastamento da atividade nesse grupo de servidores. Estes dados médicos do PCMSO indicavam a importância do esforço físico, do carregamento de peso e da própria operação do equipamento costal.

Após a realização de observações abertas e do acompanhamento das atividades de campo, ouvindo os operadores e representantes da direção da organização, a demanda inicial foi reformulada, sendo levantada a hipótese de uma combinação sinérgica de agentes agressivos presentes no trabalho do "desin", sobrepondo-se à exposição aos produtos químicos o ruído, o calor decorrente da exposição solar e do metabolismo, associado ao carregamento e à movimentação de peso, numa condição de exigência de uso de um grande número de protetores individuais para a minimização dos efeitos dos agentes agressivos.

No controle destas epidemias a SUCEN possuía em 2002 cerca de 600 desinsetizadores, "desins" distribuídos em 10 regionais do Estado de São Paulo. Por desinsetizador ou "desin" entende-se o profissional de saúde pública, em épocas anteriores denominados de "guardas de endemias".

A demanda inicial formulada tanto pela direção da autarquia, pelos representantes do Sindicato dos Trabalhadores (SINDISAÚDE) bem como pelas Comissões de Saúde do Trabalhador (COMSATs) indicava a priorização para o controle da exposição dos "desin" aos riscos químicos, representados pelos produtos usados no abate de insetos e vetores.

No decorrer da atuação da equipe multidisciplinar (um engenheiro de segurança, dois médicos do trabalho, um técnico de segurança e uma secretária) foram trazidos à tona outros agravos à saúde dos trabalhadores. Os exames audiométricos dos "desins" que aplicam regularmente inseticidas, realizados no período de 2001/2002, 33 audiometrias apresentaram alterações suspeitas de perda auditiva relacionada ao ruído, sendo que seis destes puderam ser confirmados. Vale, entretanto, citar que neste
O presente artigo propõe-se a apresentar os resultados da análise das condições de trabalho do "desin", com destaque para as avaliações dos agentes ambientais como ruído e calor durante a aplicação de inseticidas, bem como a indicação de algumas medidas de controle e minimização dos riscos no trabalho.

\section{CARACTERIZACÃO DA TAREFA DOS "DESIN"}

Os "desin" têm como tarefa principal o controle de vetores com utilização de meios químicos, mecânicos ou outras formas de remoção de agentes prejudiciais à saúde da população. A ação de controle químico de vetores tem sido gradativamente descentralizada no Estado de São Paulo, sendo transferido seu gerenciamento e execução aos municípios. Tal situação remete para a necessidade de orientação e gerenciamento seguro dos riscos implicados nestas aplicações.

Com a incidência das epidemias que atingem as populações urbanas, como as de dengue, leishmaniose e outras, os "desin" na SUCEN eram organizados em equipes de 3 a 5 pessoas com a atribuição de aplicar inseticidas 
(piretróides ou organofosforados) no ambiente peridomiciliar com a finalidade de matar os insetos adultos, de modo a evitar a propagação da doença. Os trabalhadores realizam suas tarefas em ambiente aberto, durante 3-4h/dia, com exposição direta a carga solar e altas temperaturas uma vez que as epidemias de dengue ocorrem nos períodos de verão e nas regiões mais quentes do Estado de São Paulo. Nos meses de novembro a março algumas regiões do Estado podem atingir temperaturas bastante elevadas, como em Andradina, por exemplo, que registrou em novembro de 2001 temperatura média máxima de $32,4^{\circ} \mathrm{C}$, com picos de $37^{\circ} \mathrm{C}$ em vários dias do mês, fenômeno este que se repete em várias cidades do interior de São Paulo nos meses de verão (ESCRITÓRIO DE DESENVOLVIMENTO RURAL DE ARAÇATUBA, 2001).

A nebulização ambiental mais eficaz é a realizada com o pulverizador costal motorizado, uma vez que este equipamento dá maior mobilidade e possibilita o acesso a quintais, varandas, jardins etc. A aplicação de inseticidas ocorre durante cerca de 3-4 horas por dia, no período da manhã, em ambiente aberto que inclui os quintais, garagens, implicando em ingresso nos domicílios. Uma equipe de aplicação é composta normalmente por quatro "desins" e um supervisor, e consegue cobrir por dia em média de quatro a seis quarteirões. A equipe se desloca da sede da SUCEN em uma viatura (normalmente uma camionete cabine dupla) que abriga na carroceria os pulverizadores e demais insumos usados na tarefa. A equipe se divide em duas turmas, de modo que cada dupla cobre um quarteirão por vez.

Antes da aplicação propriamente dita é feita, por um dos membros da dupla, a preparação dos quarteirões, que consiste em avisar os moradores, solicitando destes a colaboração para o preparo das residências (cobrir alimentos, retirar animais e pássaros, permanecer fora de casa durante e depois da aplicação). A aplicação do inseticida pode ocorrer no horário das refeições, o que normalmente acarreta dificuldades e conflito na relação com os moradores. Em algumas regiões, como favelas e áreas periféricas das grandes cidades, o "desin" pode se deparar com gangues envolvidas em roubos e tráfico de drogas, com risco de assaltos e violência no acesso a estes territórios.

A SUCEN utiliza-se atualmente do pulverizador costal motorizado, que foi adaptado da agricultura para uso em saúde pública após pequenas modificações no equipamento original, como o ajuste no bico dosador para acerto do tamanho da gota lançada. A Figura 1 apresenta o pulverizador costal motorizado e seus principais componentes.

Figura 1: Pulverizador costal motorizado.

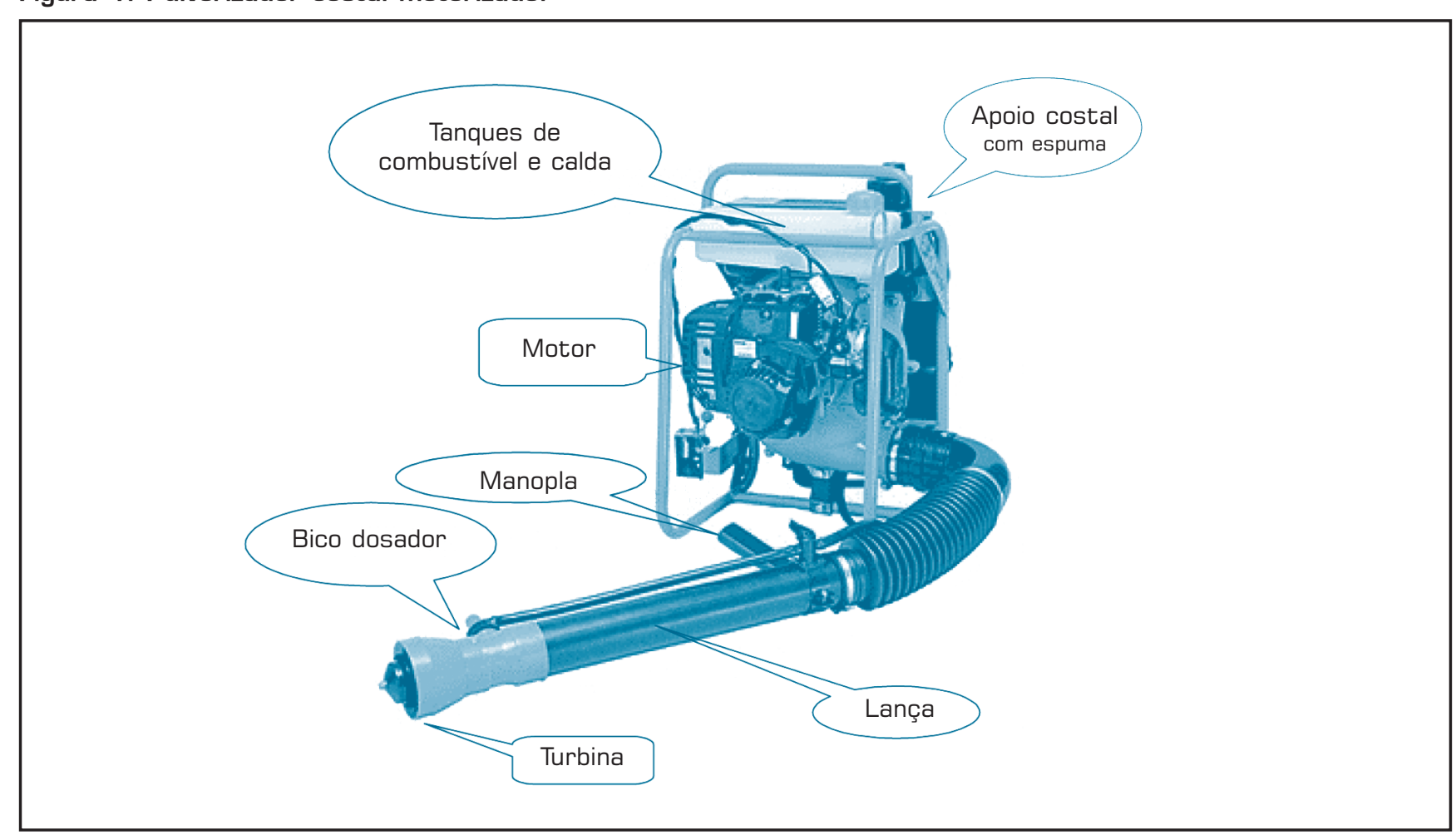




\section{Características do pulverizador:}

- Motor 2 tempos - gasolina; • Potência: 2,6 hp; • Rotação: $8000 \mathrm{rpm} ; \bullet$ Peso vazio: $11,7 \mathrm{~kg} ; \bullet$ Peso cheio (carregado): $15 \mathrm{~kg}$; • Peso da estrutura tubular de aço: $3,5 \mathrm{~kg}$; • Tamanho da gota pulverizada: $5-10_{\mathrm{m}} ; \bullet$ Ignição eletrônica com acionamento manual por cabo; - Volume de ar gerado: $12,6 \mathrm{~m}^{3}$ por $\mathrm{min}$.

A pulverização ou nebulização de inseticidas implica na exposição dos trabalhadores a diversos agentes agressivos à saúde. Agentes físicos e ambientais (calor, vibração, ruído, inseticidas); risco de acidentes e constrangimentos de ordem ergonômica (esforço, posturas, carregamento de peso, pressão e conflitos com a comunidade). Tais exposições implicam na necessidade de um programa de proteção respiratória, proteção da pele, do rosto, dos olhos e medidas de higiene pessoal para minimizar o contato mantido com estes produtos. Diante da emergência das epidemias cabe ao "desin" produzir e espalhar uma névoa intensa de produtos tóxicos (que os trabalhadores reconhecem como "veneno") que se depositam em objetos, paredes, árvores, animais, nos trabalhadores da equipe e na própria população. Nesta situação, o Equipamento de Proteção Individual (EPI), mesmo reconhecido como um paliativo, traz algum resultado no sentido de minimizar os efeitos de uma exposição bastante significativa.

A Foto 1 mostra o posicionamento do equipamento costal e os aparatos de proteção utilizados na nebulização de inseticidas durante o controle da dengue.

\section{REVISÃO BIBLIOGRÁFICA}

O ruído presente nos ambientes e processos de trabalho é responsável por vários efeitos negativos à saúde dos trabalhadores, como a lesão das células ciliares, levando à surdez progressiva e permanente, além de zumbido, irritabilidade, dificuldade de concentração, risco de acidentes e outros (SANTOS, 1994).

Pesquisa e ensaios em equipamento costal motorizado semelhante ao usado pela SUCEN encontraram níveis de ruído de $93 \mathrm{~dB}(\mathrm{~A})$, medidos na altura do ouvido do operador. Foram também encontrados níveis importantes de vibração em valores-pico de $16 \mathrm{~m} / \mathrm{sec}^{2}$. As principais fontes de ruído e vibração, segundo o autor, são a freqüência de combustão (firing frequency) que ocorre no motor, o abastecimento de ar e o barulho aerodinâmico emitido pelo soprador (rotor). Este último é responsável por um ruído elevado em frequiências bastante altas (acima de $10 \mathrm{kHz}$ ) (BANSAL,1998). O autor foca seus ensaios na redução da vibração obtida pelo balanceamento mecânico do equipamento, encontrando reduções importantes da vibração nos ombros dos operadores (de 26$38 \%$ ), resultando em considerável alívio para os mesmos. Tandon et al. (1998) realizam avaliação das fontes de ruído e estudam medidas de atenuação com uso de mantas de absorção em motogerador a gasolina. Segundo os autores, o enclausuramento parcial deste tipo de equipamento obteve resultados importantes de atenuação, da ordem de $8,5 \mathrm{~dB}(\mathrm{~A})$ em um dos lados do equipamento e em torno de $4 \mathrm{~dB}(\mathrm{~A})$ em outras faces. Este tipo de solução

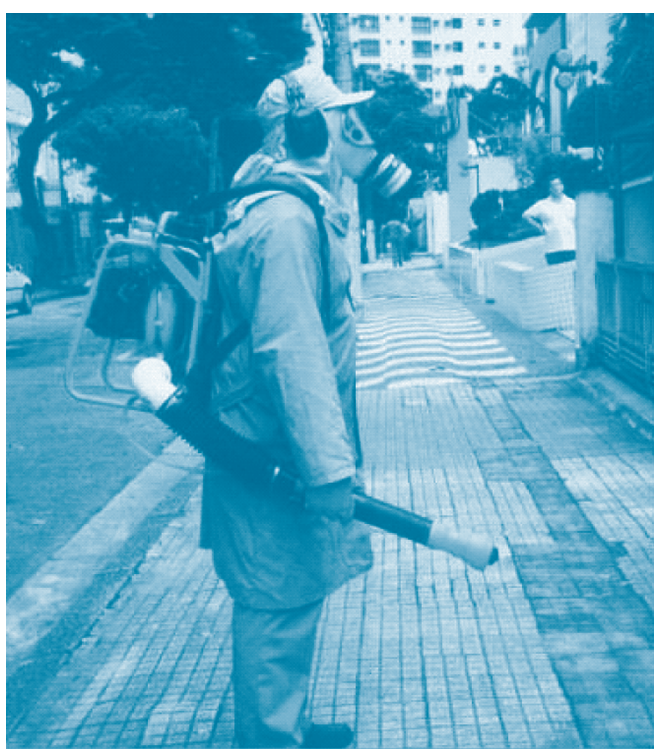

Detalhes: Posicionamento do equipamento costal. Uso de EPIs: proteção respiratória - máscara facial completa com filtro classe P2 para vapores orgânicos e névoas, proteção auditiva: protetor auricular tipo concha; proteção para a pele: avental de algodão grosso sem impermeabilização; proteção do pescoço com touca tipo legendário; proteção para a cabeça com boné; botina de segurança. Carregamento contínuo de peso durante a aplicação. 
implicou em aumento de temperatura do equipamento, mas sem comprometer sua segurança. A adição de barreiras acústicas implica também em acréscimo de peso, representando uma limitação para equipamentos costais.

Quanto ao desgaste provocado pelo carregamento de peso, Grandjean (1998) considera que um trabalhador com um consumo calórico de $250 \mathrm{kcal} / \mathrm{h}$ pode percorrer no máximo uma distância de $3,9 \mathrm{~km}$ com uma carga de 20 $\mathrm{kg}$ posicionada nas costas (tipo mochila). A despeito da similaridade da situação encontrada na SUCEN quanto à distância percorrida e ao peso carregado, não fica claro no estudo em que condições climáticas ocorre esta atividade nem o tipo de vestimenta usado.

A exposição a calor excessivo pode acarretar riscos graves à saúde dos trabalhadores. Nesta condição, a sudorese (perda de líquidos pela pele) é um dos mecanismos fundamentais para a regulação da temperatura interna do corpo, que ocorre através da evaporação. Através da evaporação do suor o corpo perde calor para o meio ambiente. Caso a sudorese e a vasodilatação periférica não sejam suficientes para manter a temperatura interna do corpo em torno de $37^{\circ} \mathrm{C}$ poderá haver conseqüências perigosas para o organismo, como a desidratação, câimbras de calor, desmaios e choque térmico (SALIBA, 2000). A perda de peso é uma referência importante do desgaste dos trabalhadores. A desidratação traz efeitos adversos que variam de modo gradativo, iniciando-se por sintomas de sede até distúrbios renais em casos mais críticos. Assim, os efeitos adversos da desidratação podem ser relacionados à porcentagem de perda de peso corpóreo. Para perda de peso de 0 a $1 \%$ o efeito causado será de sede, para perda de $2 \%$ de sede mais forte, desconforto vago e perda de apetite; para 3\% diminuição do volume sanguíneo, enfraquecimento da performance física; para $4 \%$, aumento do esforço para trabalho físico, náusea; para 5\%, dificuldade na concentração; para $6 \%$, deficiência na regularização de temperatura excessiva; para $8 \%$, vertigem, respiração difícil com exercício, aumento da fraqueza; para $10 \%$, espasmos musculares, delírio e insônia; e para 11\%, incapacidade para diminuir o volume sanguíneo para a circulação normal, deficiência da função renal (GREENLEAF, 1982); (MAHAN \& KRAUSE, 1995). Condições globais de saúde, como, por exemplo, o estado nutricional, podem interferir na reação corpórea à sobrecarga térmica. A obesidade pode atuar na produção do suor e/ou na evaporação, aumentando a susceptibilidade aos danos provocados pela sobrecarga térmica. Neste mesmo sentido, a condição de malnutrição pode reduzir a efetividade do mecanismo de produção de suor e, por conseguinte, atuar na resposta circulatória à sobrecarga térmica. A medida utilizada para avaliação do estado nutricional entre adultos é o índice de massa corpórea (IMC), ou índice de Quetelet. Este índice define o nível de adiposidade e é calculado através da relação peso $(\mathrm{kg}) /$ altura (metro) (BRAY\&GRAY, 1988; COHEN, 1990).

\section{MÉTODO}

Tendo em vista a inter-relação entre os diversos agentes que compõem a carga de trabalho do "desin" e a demanda reformulada, que indicava a prioridade para os agentes ambientais como ruído e calor, optou-se por realizar a análise ergonômica do trabalho (GUERIN et al., 2001). O método se justifica pela necessidade de uma compreensão global do trabalho do "desin", de modo a evitar uma análise fragmentada dos fatores de risco, buscando entender como estes fatores se apresentam em situação concreta de trabalho.

\section{— oram efetuadas observações diretas em campo, reuniões com os trabalhadores e com diferentes níveis hierárquicos para a compreensão da tarefa do "desin".}

Foram efetuadas observações diretas em campo, reuniões com os trabalhadores e com diferentes níveis hierárquicos para a compreensão da tarefa do "desin", para a reformulação da demanda e para a validação dos resultados finais.

A análise do trabalho do "desin" foi efetuada com acompanhamento e filmagem durante toda a jornada de trabalho. Foram gravados em vídeo cinco dias de trabalho nas cidades de São Paulo, Campinas, Barretos, São José do Rio Preto e São Vicente. Nestas fitas buscou-se observar de perto o comportamento dos operadores na relação com os moradores durante a atividade de nebulização, de modo a compreender a variabilidade e as dificuldades presentes no cumprimento da tarefa. Foi selecionada como variável de observação a manutenção do equipamento ligado pulverizando (alta rotação) e em compasso de espera (baixa rotação) enquanto o "desin" espera o término da ação de preparação das casas pelo colega de equipe. As fitas foram usadas para observação da atividade e quantificação desta variável em relação ao tempo.

Os agentes ambientais como ruído e calor foram quantificados. Realizou-se a avaliação da exposição a 
ruído durante a atividade de nebulização através de dosimetria, indicada para uma melhor caracterização da exposição dos trabalhadores levando em conta os intervalos e o ritmo da aplicação. A dosimetria foi feita pelo Centro de Referência em Saúde do Trabalhador (CEREST) - SP, no ano de 2002, utilizando-se de Dosímetro Larson \& Davis, tendo como base as normas da Fundacentro (1999). A emissão do ruído emitido pelo equipamento foi caracterizada através da medição das faixas de freqüência, através de convênio firmado pela SUCEN com o Laboratório de Vibro-acústica da Faculdade de Engenharia Mecânica da UNICAMP. indo à frente do "desin" para corrigir problemas freqüentes encontrados no interior das residências (presença de pessoas e animais, comida exposta, etc.). Observou-se que é muito comum a ocorrência destes incidentes, chegando a situações de conflito com os moradores, o que acarreta um aumento no tempo de espera com conseqüente exposição aos agentes acima do tempo teoricamente esperado, e o desgaste dos aplicadores. O Gráfico 1 mostra a duração da exposição do aplicador ao ruído da motobomba, mostrando três situações bastante diferentes. O tempo total de duração das aplicações variou de 29 minutos na quadra 1 - a nebulização mais rápida - até 56 minutos, a pulverização mais demorada, na última quadra. Estão representadas no gráfico, para cada uma das três situações, a somatória dos períodos em que o pulverizador está em alta rotação, isto é, o tempo de aplicação (tempo útil com o pulverizador ligado e nebulizando), assim

Para a avaliação do calor foi realizada a avaliação de sobrecarga térmica através do Índice de Bulbo Úmido Termômetro de Globo, usando a Norma para avaliação da exposição ocupacional ao calor- NHT - 01 C/E - 1985.

Para avaliação do desgaste envolvido na atividade física, combinado com a exposição ao calor, foi realizada a medição de peso corpóreo de um grupo de trabalhadores antes e depois da nebulização - grupo de expostos e não-expostos. Os trabalhadores expostos e não-expostos foram pesados antes e depois da jornada normal de trabalho. Durante este período foi feito o controle de ingestão de líquidos e das atividades fisiológicas do grupo de trabalhadores. Dados sobre a altura foram retirados dos prontuários médicos, com finalidade de determinar o IMC.

\section{RESULTADOS}

\section{A organização do trabalho do "desin" - Tempo de aplicação e tempo de espera com o pulverizador nas costas.}

$\mathrm{Na}$ análise ergonômica do trabalho, foi observada uma longa espera do "desin" com o pulverizador ligado e com todos os apetrechos de proteção, no aguardo da saída dos moradores de suas dependências para dar início à aplicação naquele domicílio. Trabalhando em duplas, um dos "desin" inicia sua atividade avisando o quarteirão de que será iniciada a aplicação e solicitando a colaboração de todos para uma aplicação eficiente e sem maiores riscos. Após este primeiro aviso, o "desin" que esteve na espera inicia a aplicação nos domicílios. O colega que antes estava percorrendo o quarteirão avisando os moradores do início da aplicação passa a operar como um "batedor" como a somatória dos períodos em que o pulverizador está em baixa rotação, ou seja, representando um "tempo morto". Entende-se por "tempo morto" o tempo em que o "desin" fica parado no portão, com o equipamento nas costas, ligado e com exposição solar, no aguardo da saída das pessoas e da preparação final das residências. Tal situação revela uma variabilidade intensa no trabalho do "desin" e sugere a necessidade de um melhor planejamento e preparação antes de dar início à atividade de aplicação, o que, no caso, pode significar o aumento do tamanho da equipe para três agentes.

\section{Avaliação do ruído}

O nível equivalente de ruído encontrado foi de 98,5 $\mathrm{dB}(\mathrm{A})$, correspondendo a uma dose de $321,6 \%$ no período de avaliação. Tal estudo revelou que mesmo usando um protetor auricular tipo concha, considerando uma proteção com nível médio de redução e nível de atenuação teórica NRR de $25 \mathrm{~dB}(\mathrm{~A})$ ainda permanece uma Exposição Remanescente de 86,3 dB(A). Diante de tal situação, a SUCEN adotou o uso de dois protetores auriculares (uso combinado de protetor concha e protetor tipo inserção de silicone flangeado).

\section{Avaliação da sobrecarga térmica}

Apresentamos a seguir o resumo dos dados obtidos em avaliação do calor ambiental realizada em Araçatuba, SP, no mês de fevereiro de 2001. Mediu-se em dia típico de atividade o índice de Bulbo Úmido Termômetro de Globo médio de $29,3^{\circ} \mathrm{C}$ para a exposição solar, na hora mais crítica. A taxa de metabolismo ponderada considerando regime de 30' de trabalho e 30' de aviso (alternan- 
do a atividade - adotou-se o metabolismo de $335 \mathrm{kcal} / \mathrm{h}$ para a aplicação e $180 \mathrm{kcal} / \mathrm{h}$ para a atividade de aviso de casa em casa), resultando em metabolismo médio de 257,5 kcal/h. De acordo com a NR 15 da Portaria 3214/ 78, o Limite de Tolerância para o Metabolismo Calculado é IBUTG de $25,5^{\circ} \mathrm{C}$, considerando o fator roupa "clo" igual a dois (dois) devido ao uso de equipamento de proteção individual e uniforme, conforme parâmetro adotado pela ACGIH (1999). Observa-se, portanto, que a exposição solar e o tipo de atividade de nebulização implicam em exposição que excede o limite de tolerância preconizado pela legislação e normas técnicas vigentes.

\section{Perda de peso corporal durante uma jornada de trabalho na nebulização: desgaste fisiológico do "desin".}

Na Tabela 1 apresentamos o resultado da perda de peso corporal do "desin" durante uma jornada de trabalho para um grupo de 10 trabalhadores expostos à carga solar. Observou-se no grupo exposto ao calor uma perda média de peso de 2,31\% de peso corpóreo, após as quatro horas de atividade de aplicação de inseticidas. No grupocontrole (não-expostos) a perda de peso atingiu uma média de $1,71 \%$ de peso corpóreo. Os trabalhadores que se encontram na faixa recomendada de Índice de Massa Corpórea (IMC) apresentaram a média de $1,94 \%$ de perda de peso. Um trabalhador pertencente à faixa de IMC abaixo da faixa recomendada apresentou perda de peso de $1,30 \%$. Os trabalhadores com IMC acima da faixa recomendada, pertencentes a diferentes categorias de obesidade, apresentaram uma média de perda de peso de $2,36 \%$. Observa-se na tabela 1 que um dos trabalhadores, que operou em regime contínuo sem revezamento com os colegas, aplicando inseticidas durante $42^{\prime}$ com pausa de $12^{\prime}$ de descanso em sombra perdeu $5 \%$ de peso corpóreo, o que representa risco grave à saúde.

\section{DIAGNÓSTICO E RECOMENDACÕES}

"Não basta descrever e produzir fatos; não se pode escapar da tarefa que consiste em elaborar seu sentido." Pierre Grieco in Guerin et al., 2001, p.137

No desenrolar do presente estudo e das ações desenvolvidas podemos firmar um diagnóstico de que o trabalho do "desin" o expõe a uma ação combinada de agentes agressivos e de efeitos sinérgicos. A exposição aos agentes químicos e ao ruído do equipamento é potencializada pela exposição ao calor, que implica em abertura dos poros da pele (uma via fundamental para o ingresso dos produtos químicos). Esta situação implica também na dificuldade ou quase impossibilidade de uso dos equipamentos de proteção individual, que por sua vez potencializa a carga metabólica, que também é agravada pelo carregamento de peso excessivo do nebulizador motorizado.

O ruído, por sua magnitude, implica na necessidade de uso combinado de dois protetores auriculares (inserção mais o de concha), que traz dificuldade na comunicação

Tabela 1: Sobrecarga solar e perda de peso corpóreo na nebulização costal.

\begin{tabular}{|c|c|c|c|c|c|}
\hline $\begin{array}{l}\text { TRABALHADOR } \\
\text { EXPOSTO }\end{array}$ & $\begin{array}{l}\text { REGIME DE } \\
\text { TRABALHO }\end{array}$ & $\begin{array}{l}\text { PESO INICIAL } \\
\text { (KG) }\end{array}$ & $\begin{array}{l}\text { PESO FINAL } \\
\text { (KG) }\end{array}$ & $\begin{array}{l}\text { DIFERENÇA DE } \\
\text { PESO (KG) }\end{array}$ & $\begin{array}{l}\text { PERDA DE } \\
\text { PESO \% }\end{array}$ \\
\hline$A$ & Revezamento & 68,80 & 67,20 & 1,60 & 2,32 \\
\hline$B$ & Revezamento & 63,10 & 62,10 & 1,00 & 1,58 \\
\hline $\mathrm{C}$ & Revezamento & 75,50 & 74,00 & 1,50 & 1,98 \\
\hline $\mathrm{D}$ & Revezamento & 119,0 & 116,0 & 2,40 & 2,01 \\
\hline$E$ & Revezamento & 82,00 & 80,50 & 1,50 & 1,82 \\
\hline $\mathrm{F}$ & Revezamento & 73,10 & 71,10 & 2,00 & 2,73 \\
\hline G & Revezamento & 71,30 & $70 ., 00$ & 1,66 & 2,32 \\
\hline $\mathrm{H}$ & Revezamento & 83,00 & 82,00 & 1,70 & 2,04 \\
\hline 1 & Contínuo & 87,90 & 83,50 & 4,40 & 5,00 \\
\hline 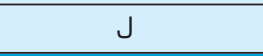 & Revezamento & 53,70 & 53,00 & 0,70 & 1,30 \\
\hline \multicolumn{6}{|c|}{ TRABALHADOR NÃO-EXPOSTO } \\
\hline $\mathrm{K}$ & Contínuo & 89,00 & 87,80 & 1,20 & 1,34 \\
\hline $\mathrm{L}$ & Contínuo & 74,50 & 73,60 & 1,44 & 1,93 \\
\hline$M$ & Contínuo & 70,20 & 68,80 & 1,46 & 2,07 \\
\hline
\end{tabular}


com o colega da equipe e com a população usuária, aumentando o risco de acidentes. De outro modo, a organização do trabalho por duplas em cada quadra revelou-se insuficiente, repercutindo na demora da desinsetização, uma vez que é freqüente a ocorrência de interrupções e conflitos com os moradores, pois as casas normalmente não estão preparadas para o início das aplicações, aumentando a carga de trabalho e o desgaste dos "desin". pamento. Foram então efetuados testes com alterações no escapamento do pulverizador. Um dos ensaios foi com a introdução de um escapamento de mobilete na saída do escapamento original do pulverizador (UNICAMP, 2001). Os ensaios mostraram que a medida não foi satisfatória, atenuando os níveis de ruído em 2 - $3 \mathrm{~dB}(\mathrm{~A})$ medidos na altura do ouvido do usuário. Usando escapamento absoluto (que isola todo o ruído emitido pelos gases de escape) foi medida uma atenuação de $4-6$ $\mathrm{dB}(\mathrm{A})$, o que aponta que o escapamento é uma fonte significativa de ruído, mas que são necessárias outras medidas de engenharia para redução do ruído na fonte.

Em um segundo ensaio conduzido no mesmo Laboratório de Vibroacús-

$\mathrm{Na}$ tentativa de encontrar uma alternativa ao problema do ruído, no Laboratório de Vibroacústica da UNICAMP$\mathrm{SP}$, foram efetuados ensaios para minimização do ruído gerado pelo pulverizador costal motorizado. Avaliou-se inicialmente que o escapamento teria um papel importante na geração e propagação do ruído emitido pelo equi- tica da UNICAMP (TUON, 2001) foram utilizadas mantas de absorção e isolamento acústico para atenuação do ruído que alcança a zona auditiva do operador. Foram utilizadas mantas de material denominado Thinsulate, fabricado pela $3 \mathrm{M}$, revestidas com uma chapa de aço para sustentação. O Gráfico 2 mostra o ruído emitido pelo

Gráfico 1: Duração total da nebulização em três quadras diferentes. Comparação do tempo em que a motobomba permaneceu em alta rotação (nebulizando) e em baixa rotação (esperando o término da preparação das casas].

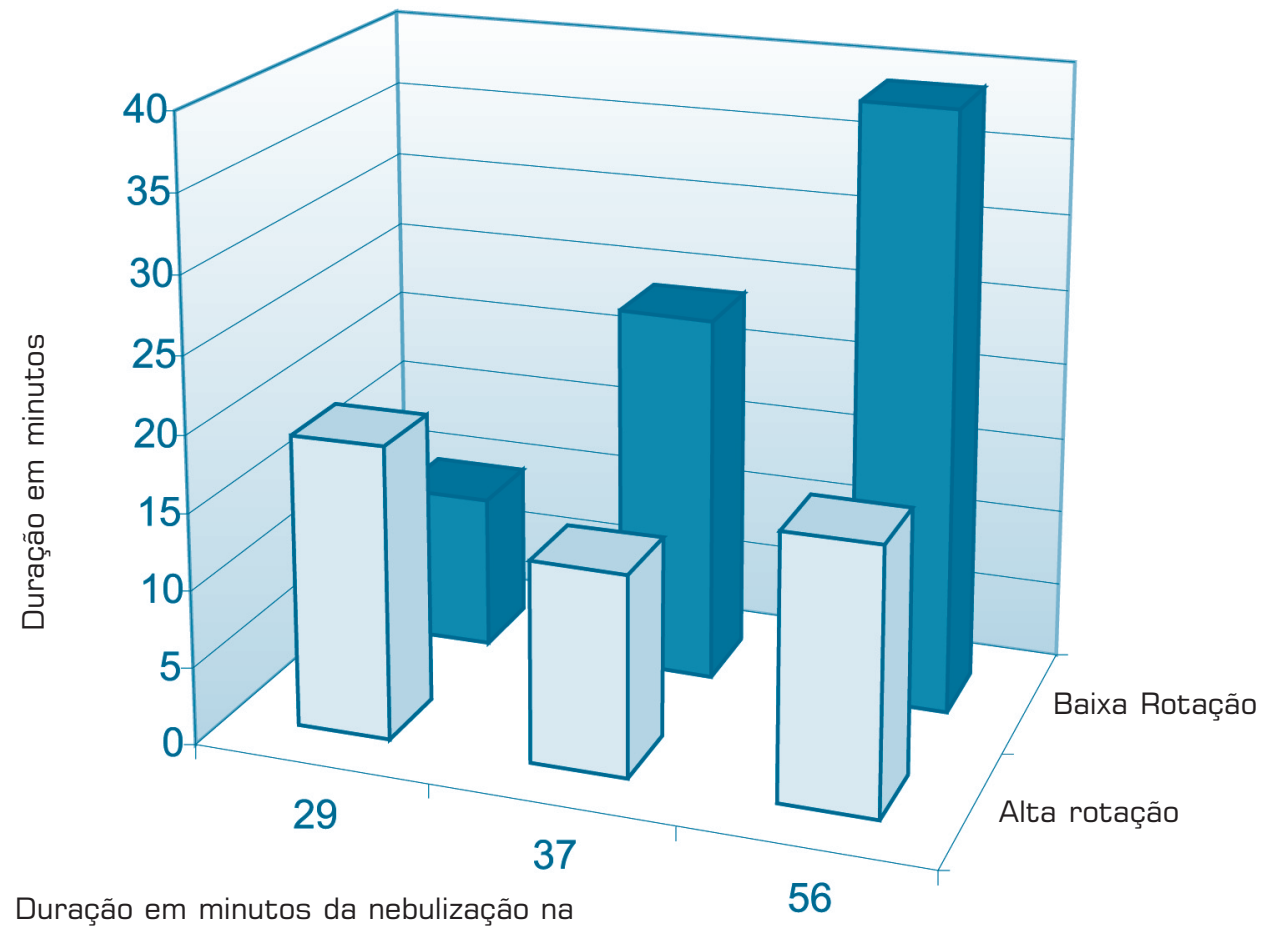

quadra 1 (tempo total 29'), quadra 2 (tempo

total 37') e quadra 3 (tempo total) 56'. 
nebulizador com e sem aplicação de mantas de proteção acústica em faixas de freqüência distribuídas em bandas de oitava (TUON, 2001).

Devido às características da emissão de ruído com predominância nas faixas de baixa frequiência, as medidas para redução testadas não apresentaram resultados satisfatórios, sendo ainda indispensável o uso de protetores auriculares e acompanhamento médico, incluindo a melhoria na cobertura dos exames audiométricos. Novos estudos de engenharia são necessários para a redução dos riscos gerados por este equipamento, o que remete para a necessidade de uma maior responsabilização e envolvimento dos fabricantes na fase de concepção e projeto de tais produtos, antes da colocação dos mesmos no mercado.

A minimização do desgaste decorrente da exposição aos agentes químicos, no caso do controle da dengue, passa pela mudança completa deste processo de trabalho, que poderá ser obtida entre outras medidas pela substituição dos produtos químicos, bem como pela participação da comunidade no sentido de prevenir a proliferação e criação dos mosquitos.
A proteção individual contra os riscos químicos agrava o desgaste causado pelo metabolismo (esforço físico) e pela exposição solar, representando uma carga adicional na atividade do "desin", sendo fundamental a busca de opções que minimizem ou eliminem o uso dos inseticidas no controle de vetores. A substituição dos produtos atualmente usados por agentes menos agressivos poderá representar no futuro uma redução significativa do impacto ambiental da atividade ora estudada tanto para os trabalhadores como para a comunidade e o meio ambiente.

Quanto à perda de peso e de líquidos pela transpiração, observa-se que a atividade representa risco à saúde dos trabalhadores, especialmente para aqueles que apresentam IMC mais afastado da faixa mediana. Os trabalhadores com baixo índice de IMC apresentam dificuldade de dissipação de calor por via da sudorese, enquanto que os obesos perdem uma maior quantidade de líquidos e sais, o que pode afetar o equilíbrio fisiológico.

O carregamento de peso, os esforços físicos e a associação com os riscos decorrentes da exposição solar em ambiente aberto, agravados pelo uso de roupas e equipamentos pesados de proteção individual, eviden-

Gráfico 2: Rúdo emitido pelo nebulizador com e sem aplicação de mantas de proteção acústica em faixas de frequência distribuidas em bandas de oitava.

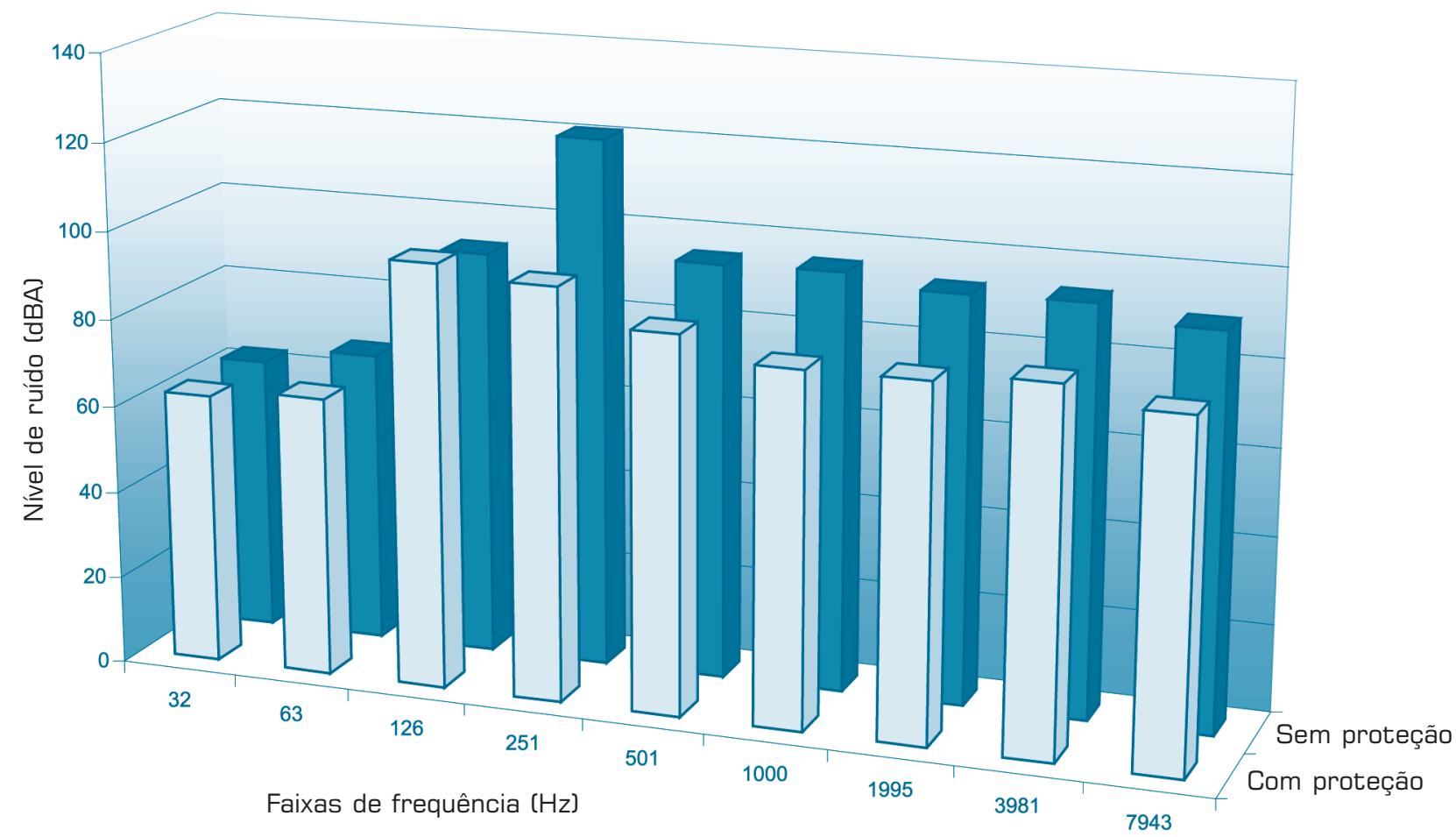


ciam a necessidade das pausas regulares e o revezamento entre os trabalhadores expostos, de modo a minimizar os riscos de lombalgias e doenças osteomusculares, além dos riscos decorrentes da exposição aos produtos químicos e ao ruído. Além destas medidas é importante a ingestão de líquidos específicos para tais situações, de modo a compensar a perda decorrente da sudorese, e o acompanhamento médico sistemático.

Maior conscientização dos moradores, associada a uma melhor organização do trabalho e ao aumento da equipe para três pessoas podem facilitar a atividade do "desin", diminuindo os conflitos e o desgaste observados nas atividades de campo.

\section{VALIDAC̣ÃO E CONSIDERAC̣ÕES FINAIS}

Os resultados globais do estudo foram apresentados aos interlocutores da autarquia em distintos momentos e espaços. Os trabalhadores participaram de cursos e palestras e reuniões regionais, eventos estes que contaram com a participação de cerca de $90 \%$ dos trabalhadores, com a finalidade de apresentar e discutir os resultados. As reuniões com dirigentes propiciaram revelar elementos do trabalho real dos "desin" desconhecidos pelos planejadores, fornecendo a estes indicações para melhoria nos equipamentos e na forma de organização do trabalho.

A atuação em equipe multiprofissional na análise do trabalho dos aplicadores, com método que contou com a participação direta dos envolvidos, revelou-se como apropriada para uma melhor compreensão da riqueza e complexidade desta situação de trabalho. Novos estudos com análise ergonômica da atividade, como preconizado por Guerin et al. (2001), poderão contribuir para revelar com mais detalhe o comportamento dos operadores diante dos constrangimentos enfrentados, bem como as estratégias de regulação adotadas pelos trabalhadores no desenvolvimento da atividade de trabalho.

\section{Artigo recebido em 20/09/2004 Aprovado para publicação em 21/06/2005}

\section{- Referências Bibliográficas}

\begin{abstract}
AMERICAN CONFERENCE OF GOVERNMENTAL INDUSTRIAL HYGIENISTS. ACGIH. Limites de Exposição para substâncias químicas e agentes físicos, ACGIH, 1999.

BANSAL, A.S. Dynamic Response and Vibration Control at the Source in a Powered - Knapsack Sprayer. V. 29, n. 3 Agricultural mechanization in Asia, Africa and Latin America. 1998.
\end{abstract}

BRAY, G.A; GRAY, D.S. Obesity. WEST J.Med, 1988.

COHEN, R. Injuries due to Physical Hazards - In: LADOU J. Occupational Medicine, Appleton e Lange Cunnictut - USA, 1990.
ESCRITÓRIO DE DESENVOLVIMENTO RURAL DE ARACATUBA. Observações Termo-Pluviométricas, Município de Andradina, SP. Coordenadoria de Assistência Técnica Integral - CATI, Secretaria de Agricultura e Abastecimento. Mimeo, 2001.

FUNDACENTRO. Norma para avaliação da exposição ocupacional ao ruído - NHO 01. SP, 1999.

GRANDJEAN, E. Manual de Ergonomia. Adaptando o Trabalho ao Homem. Porto Alegre. 4. ed. Bookman, 1998.
GREENLEAF, J.E.: The body's need for fluids. In: HASKELL W., SCALA J., and WHITTEN J. [eds.]. Nutrition and Athletic Performance. Palo Alto, CA Bull Publishing Co, 1982.

GUÉRIN, F. et all. Compreender o Trabalho para Transformá-lo. São Paulo. Ed. Edgard Blucher, 2001.

MAHAN, L.K; KRAUSE, S.E.S: Alimento, Nutrição e Dietoterapia. 8. ed. Roca, 1995.

SALIBA, T.M. Manual Prático de Avaliação e Controle de Calor - PPRA. São Paulo, Ed. LTR, 2000.

SANTOS, U.P. Ruídos, Riscos e Prevenção. São Paulo: HUCITEC, 1994.
TANDON, N.; NAKRA, B.C.; UBHE, D.R.; KILLA, N.K. Noise Control of Engine Drive Portable Generator Set. Applied Acoustic. v. 55. n. 4 p. 307-328, 1998.

TUON, L.R. Estudo Experimental sobre o ruído emitido por um atomizador Multispray com proposta de enclausuramento parcial e tratamento acústico. Monografia de Graduação. UNICAMP, SP, 2001. Mimeo, 51 p.

UNICAMP. Análise acústica de pulverizadores costais da SUCEN. Laboratório de Vibroacústica. UNICAMP, 2001. Mimeo, $10 \mathrm{p}$.

- Sobre o autor

\section{Rodolfo Andrade de Gouveia VILELA}

Prof. Dr. do Programa de Pós-Graduação em Engenharia de Produção da UNIMEP. Coordenador do Centro de Referência em Saúde do Trabalhador de Piracicaba.

Endereço: Rua Ipiranga, 790 - Piracicaba SP - Centro - CEP 13400-485

E-mail: ravilela@unimep.br

Tel./fax: (19) 3434-6337

\section{Maria Elizabeth MALAGOLI}

Médica do Trabalho. Profa. do Curso de Especialização em Medicina do Trabalho da Santa Casa de São Paulo.

Luiz C. MORRONE

Prof. Dr. da Faculdade de Ciências Médicas da Santa Casa de São Paulo. 